\title{
Enhancing commitments
}

\author{
COP26 will mark six years since the Paris Agreement was reached, with the ambitious $1.5^{\circ} \mathrm{C}$ warming target. After \\ the turbulent year of 2020, now is the time that countries need to commit to drive global climate action forward.
}

T he fifth anniversary of the Paris Agreement in December 2020 saw the agreement come into effect, and should have seen updated Nationally Determined Contributions presented at the Glasgow Conference of the Parties (COP). The pandemic meant the event could not go ahead, postponed for a year, and national priorities shifted to cope with the ongoing health threats. Now the lead-up to COP26 is a time for nations to refocus and will see a number of events, including the recent Leaders' Summit on Climate hosted by US President Joe Biden in April. Attended by 40 national leaders, it sent a clear message of the USA recommitting to the Paris Agreement and resulted in a series of announcements from those in attendance of enhanced ambition and new climate goals. These announcements, and more, are needed to put countries, and the world, on track for limiting warming to below $1.5^{\circ} \mathrm{C}$, and net-zero emissions by mid-century.

Lockdowns in 2020 resulted in rapid emissions reductions, but there was a quick rebound as restrictions were lifted and society returned to previous behaviours and way of life. The structural changes needed for sustained lower emissions are yet to be implemented - as discussed in our March Editorial (Nat. Clim. Change 11, 179; 2021). Enhanced commitments are the first step, as countries then determine how development and policy can be deployed to achieve those ambitions.

Looking at the wider spectrum of greenhouse gases, 2020 saw a record increase in methane - a short-lived climate forcer whose warming potential is 28 times that of $\mathrm{CO}_{2}$ over 100 years. The recent Global Methane Assessment written by the United Nations Environment Programme (UNEP) and Climate and Clean Air Coalition (CCAC) reported that three sectors - fossil fuels, waste and agriculture - are responsible for over half of the anthropogenic emissions, yet it is possible with already available measures to reduce emissions by up to $45 \%$, or $180 \mathrm{Mt}$ per year, from these sectors by 2030 . This is an example of a potential quick win on the path to achieving the Paris Agreement targets, as this cut could limit temperature

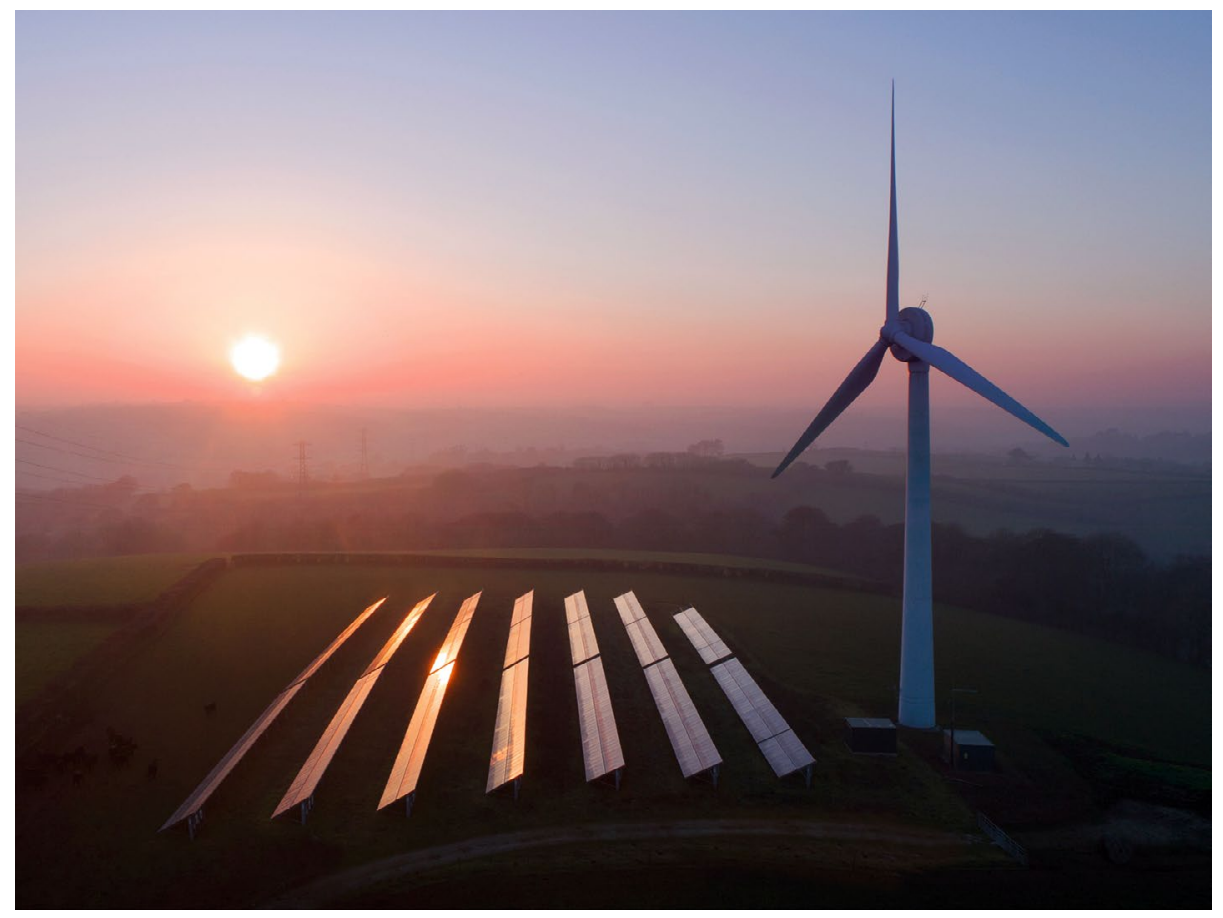

Credit: Peter Cade/Stone/Getty

increases by almost $0.3^{\circ} \mathrm{C}$. Co-benefits from reduced air pollution (methane plays a role in the formation of ground-level ozone) to health and agriculture result in methane mitigation having a financial benefit of $\sim$ US $\$ 4,300$ per tonne.

The fossil fuel sector, unsurprisingly, offers the potential for the largest methane reductions. Demand for fossil fuel declined in 2020, driven by the pandemic-related economic slowdown and lower coal power generation (Nat. Clim. Change 11, 193-196; 2021), whereas there was increased demand for renewable energy - the only energy source to experience higher demand (Renewable Energy Market Update 2021. IEA; 2021). Renewable energy capacity increased by $45 \%$, its largest year-on-year increase since 1999 , to capacity of $\sim 280 \mathrm{GW}$, with expectations that solar photovoltaic development will continue to increase in the coming years, while wind, which grew by more than $90 \%$ in 2020 , will increase at a slower rate - overall, renewables could account for $90 \%$ of new power capacity in $2021 / 2022$. This expectation is a $25 \%$ increase by the International Energy Agency on their previous report in November 2020.

Demand for low-carbon solutions, alongside policy, is needed for these technologies to become the norm. A recent review paper (Environ. Res. Lett. 16, 043007; 2021) concludes that policies that lead to induced investment, as has been seen for solar power installation, can result in energy transitions being cheaper than predicted by modelling studies.

As 2021 progresses, it will be interesting to see how different countries prioritize, and what topics emerge as the key negotiating points at COP26. The year seems full of promise with the commitments being announced, but when it comes time for action, will there be motivation and momentum to make those commitments binding?

Published online: 3 June 2021

https://doi.org/10.1038/s41558-021-01084-9 